\author{
Abdullah Aljarodi ${ }^{*}$ \\ Alex Rialp ${ }^{* *}$ \\ David Urbano***
}

\title{
FEMALE ENTREPRENEURIAL ACTIVITY IN EMERGING ECONOMIES: A SYSTEMATIC LITERATURE REVIEW
}

This study reviews systematically the existing literature on female entrepreneurial activity in emerging economies. The paper reviews articles included in the Social Science Citation Index (SSCI). Based on the main findings, the literature considers three levels of analysis: micro-individual, meso-organizational, and macro-environmental. The results show that the macro-environmental level has perceived higher attention from scholars, while several studies have incorporated the other levels of analysis.

\section{Emprendimiento femenino en economías emergentes: una revisión sistemática de la literatura}

Este artículo hace una revisión sistemática de la literatura existente sobre emprendimiento femenino en las economías emergentes. El trabajo revisa los artículos incluidos en el Social Science Citation Index (SSCI). En base a los principales hallazgos, la literatura al respecto considera tres niveles de análisis: microindividual, mesoorganizativo y macroambiental. Los resultados muestran que el nivel macroambiental es el que ha recibido mayor atención por parte de los académicos, si bien hay varios estudios que también han incorporado los otros niveles de análisis.

Keywords: female entrepreneurship, women entrepreneurship, gender, emerging economies, literature review.

Palabras clave: emprendimiento femenino, emprendimiento por mujeres, género, economías emergentes, revisión de la literatura.

JEL: M130.

\footnotetext{
* College of Business Administration, University of Business and Technology, Jeddah, Saudi Arabia.

Contacto: a.aljarodi@ubt.edu.sa

** Department of Business, Bellaterra Campus - Universitat Autònoma de Barcelona (UAB), Cerdanyola del

Vallès (Barcelona), Spain, and Department of Industrial Economics and Technology Management, Norwegian

University of Science and Technology, Trondheim, Norway.

Contacto: alex.rialp@uab.cat

*** Department of Business, Bellaterra Campus - Universitat Autònoma de Barcelona (UAB), Cerdanyola del Vallès (Barcelona), Spain and Centre for Entrepreneurship and Social Innovation Research (CREIS),

Sabadell Campus - Universitat Autònoma de Barcelona (UAB), Sabadell (Barcelona), Spain.

Contacto: david.urbano@uab.cat

Final version July 2021.

https://doi.org/10.32796/ice.2021.921.7269
} 


\section{Introduction}

Over the years, there has been a gradual increase in the levels of female self-employment that is noticeably reflected in countries' economic and social development. The GEM yearly report about individuals' and nations' entrepreneurial activity noted that the number of females who are in the process of starting, or who have already started a firm, increased from 187 million in 2010 to 263 million in 2014 (Bosma \& Levie, 2010; GEM, 2017). The available literature shows a parallel increase in research concerning women entrepreneurs from developed nations (AI-Dajani \& Marlow, 2010; Tlaiss, 2015). The present study offers a complementary analysis of the existing literature on women entrepreneurs within emerging economies.

The relevance of women entrepreneurs to economic development in both developed and developing nations greatly led us to develop this systematic literature research. Given that, the objective of the study is to systematically review the existing literature on female entrepreneurial activity in the context of emerging and developing economies. Following recent but primarily bibliometric-oriented studies in this field (Moreira et al., 2019), this paper systematically reviews articles included in the Social Science Citation Index (SSCI) for the period 2008-2018. The main contributions of the paper are the following. First, it provides updated insights on women's characteristics, motivations and obstacles creating a solid background to identify the most critical factors to understand the role of female entrepreneurs in emerging economies. Second, it discusses the protocols and approaches followed by the study of Tranfield et al. (2003) and adapted later by several other studies (e.g., Bashir et al., 2020; Gherhes et al., 2016; Moustaghfir et al., 2020; Thorpe et al., 2005) to ensure high-quality selection of journal articles. Lastly, this research provides a holistic perspective of academic studies from the last several years thus building a robust view of entrepreneurial conditions for women within their emerging and developing nations.
The review of the literature shows that the studies fall into three levels of analysis to provide an overall understanding of female entrepreneurship in emerging economies. First, at the micro level, investigations focused on the qualities possessed by female individuals for business creation in this context (Itani et al., 2011; Naser et al., 2009; Westhead \& Solesvik, 2016; Zamberi Ahmad, 2011). These individual characteristics are mainly framed by human capital theory (Becker, 2009). Secondly, at the meso level, studies sought to measure the resources and capabilities that female entrepreneurs in emerging nations need when establishing and running their firms (Bardasi et al., 2011; Lee et al., 2016; Rodríguez Gutiérrez et al., 2014). Finally, at the macro level, several studies have considered the social, political, institutional and economic environmental factors relevant to female entrepreneurship (Aidis et al., 2007; Al-Dajani \& Marlow, 2010; Welsh et al., 2014). The review documents show, at the macro level, that the use of institutional theory (North, 1990; Scott, 1995) is framed explicitly and implicitly as a way to understand entrepreneurial activity (Stephen et al., 2005; Urbano \& Alvarez, 2014; Aparicio et al., 2016).

After this brief introduction the paper is structure into four main sections. Section 2 presents the methodology. Section 3 shows the main findings of the review and discusses the results divided into three levels of analysis (micro-individual, meso-organisational, and macro-environmental). Finally, section 4 includes the conclusion along with implications, limitations and future directions.

\section{Methodology}

The explosion of academic and practice-oriented publications in the latest part of the twentieth century has led to a need for improved methods of published research evaluation (Bashir et al., 2020; Gherhes et al., 2016; Moustaghfir et al., 2020; Thorpe et al., 2005; Tranfield et al., 2003). Many authors suggest that 


\begin{tabular}{|c|c|c|c|c|}
\hline \multicolumn{5}{|c|}{ FIGURE 1} \\
\hline \multicolumn{5}{|c|}{ SUMMARY OF THE SYSTEMATIC REVIEW PROCESS AND RESULTS } \\
\hline Defining the objectives & $\longrightarrow$ & Preparing the proposal & $\longrightarrow$ & Developing the protocol \\
\hline \multicolumn{5}{|c|}{$\downarrow$} \\
\hline \multicolumn{5}{|c|}{ Conducting the review } \\
\hline Stage One & Stage Two & Stage Three & \multicolumn{2}{|c|}{ Stage Four } \\
\hline Activity & Activity & Activity & \multicolumn{2}{|c|}{ Activity } \\
\hline $\begin{array}{l}\text { Citation searches in } \\
\text { citation database }\end{array}$ & $\begin{array}{c}\text { Exclusion analysis } \\
\text { conducted and RefWorks } \\
\text { check for duplication }\end{array}$ & $\begin{array}{l}\text { Search strings used } \\
\text { to exclude further articles }\end{array}$ & \multicolumn{2}{|c|}{ Quality and relevance analysis } \\
\hline Key Results & Key Results & Key Results & \multicolumn{2}{|c|}{ Key Results } \\
\hline Databases (1) & Duplicates (8) & Abstract, title, \& keywords (38) & \multicolumn{2}{|c|}{ Relevant (23) } \\
\hline Keywords used (8) & Timeframe (34) & & \multirow{2}{*}{\multicolumn{2}{|c|}{ Less relevant (6) }} \\
\hline Citations found (221) & Language (5) & & \multirow{2}{*}{\multicolumn{2}{|c|}{ Not relevant (9) }} \\
\hline Review paper (108) & & & & \\
\hline Citations used (108) & Citations used (61) & Citations used (38) & \multicolumn{2}{|c|}{ Citations used (23) } \\
\hline \multicolumn{5}{|c|}{$\checkmark$} \\
\hline \multicolumn{5}{|c|}{ Reporting the review } \\
\hline \multicolumn{3}{|c|}{ Descriptive reporting of citations } & \multicolumn{2}{|c|}{ Thematic reporting of journal articles } \\
\hline
\end{tabular}

Systematic Reviews (SR) are an improvement upon traditional literature reviews, for several reasons: 1) a $\mathrm{SR}$ is based on a peer-reviewed protocol; 2 ) reliability of integrated research findings is increased; 3 ) pre-existing reviewer bias in selecting and evaluating studies is likely be reduced due to more strict guidelines on how to select the articles; and 4) a SR is able to assess and integrate the relevant literature related to the major research question being addressed. Therefore, a systematic review approach was deemed appropriate for conducting this present review study, and the strategy and process for this task to be done are set out in the following two subsections.

\section{Systematic Review Approach}

Prior studies suggest there are three steps that need to be followed to establish an operationalised systematic review (Gherhes et al., 2016; Tranfield et al., 2003). These steps include planning, conducting and reporting the review within several phases of activity, which are essential to presenting adequate and precise results. Tranfield et al. (2003) suggested the three main stages to outline the SR, which were later summarised by Gherhes et al. (2016). These stages are set out below, as refined for this study, together with a fourth stage dividing the results into groups for analysis (see Figure 1). 
In the first stage, the Web of Science database was selected, which facilitated this study to have a broader option to control the strings of search. Therefore, the search included one major database and eight keywords, which follow the sequence of search steps that are presented in Figure 1, comprising the review protocol. The search was limited to listed articles in the Social Sciences Citation Index (SSCI) for the period 2008-2018. Choosing articles that are included in the SSCI helps to ensure the quality of the articles (Álvarez et al., 2014). The search included qualitative and quantitative studies to serve the main aim of the research and to provide extensive evidence of female entrepreneurs' conditions within emerging economies. The keywords selected to fit the objective of the study were female entrepreneurship, women entrepreneur*, businesswomen, gender, and emerging/developing economy*. The study was restricted to only published peer-reviewed journal articles because the primary objective of this study is to focus on high quality published work. The results initially reported a total of 221 hits, but only 108 documents were retained at this first stage because many did not actually fit the scope of the review.

Next, in the second stage, the study used RefWorks software to organise the articles, identify and remove duplicates, and create bibliographies in multiple formats (McGrath, 2006). The results showed that there were 8 duplicate studies, 5 of the articles in a different language than English, and 34 articles were not within the time frame chosen for the study. Due to a well-known pioneering study about female entrepreneurship in transition economies (Aidis et al., 2007) also included in our review, we took 2008 as our cut-off year until 2018, therefore encompassing a ten-year period. Additionally, 2008 marked a time of great change due to the worldwide economic crisis (Devece et al., 2016). This filtering process resulted in 61 potential documents that could be used in this review.

These 61 potential documents (citations) were selected by already using the eight above mentioned keywords (female entrepreneurship, women entrepreneur*, businesswomen, gender, and emerging/developing economy*). The study limited the search strings to only abstract, title and keywords to restrict the scope of findings. For example, when combining the search strings 'female entrepreneurship AND emerging economy* in any of these fields of search several articles were removed as not fitting the interaction. Once the exclusion criteria were applied at this stage, 38 documents were retained.

In the fourth stage of this review analysis, it was essential to divide the studies into different groups based on relevance and our understanding of the papers. This process revealed that either some articles were not relevant enough to the scope of this study or were too mixed to understand the objective, approach, or findings clearly. We also looked deeply into the introduction section for some of the articles that seemed to be important but were too difficult to judge from the title and abstract only. To overcome this complication, we divided the articles into three groups. Group 'A' included completely relevant documents to our review scope and objective, 'B' incorporated somewhat more doubtful articles that were less clear or too complicated to understand, and ' $C$ ' was deemed for studies that were finally considered irrelevant. This last filter of quality and relevance analysis allowed us to select 23 fully relevant papers for inclusion and further analysis in the systematic review.

\section{Analysis of Systematic Search Results}

The study resulted in a limited number of articles from the top journals with high impact factor, so it was essential to seek journals that related fondly to the scope of this review, and that are included in WoS-SSCI. The final review sample included eleven articles published in the top journals in entrepreneurship (e.g., Journal of Business Venturing, Journal of Business Research, International Small Business Journal, Journal of Small Business Management, and Small Business Economics) and twelve articles from 


\begin{tabular}{|c|c|c|c|c|c|}
\hline \multirow[t]{3}{*}{ JOURNALS AND PUBLISト } & $\begin{array}{l}=1 \\
\text { D ARTIC }\end{array}$ & LES PER & YEAR & \multirow{2}{*}{\multicolumn{2}{|c|}{ Total }} \\
\hline & \multirow{2}{*}{$2008-2010$} & \multirow{2}{*}{$2011-2014$} & \multirow{2}{*}{ 2015-2018 } & & \\
\hline & & & & No. & $\%$ \\
\hline International Small Business Journal.......... & 1 & 0 & 2 & 3 & 13 \\
\hline Journal of Business Research ...................... & 0 & 1 & 1 & 2 & 9 \\
\hline Journal of Business Venturing ............................ & 0 & 1 & 0 & 1 & 4 \\
\hline 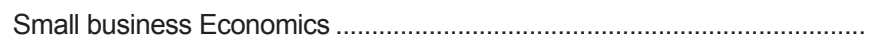 & 0 & 1 & 0 & 1 & 4 \\
\hline 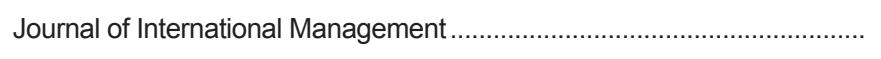 & 0 & 0 & 1 & 1 & 4 \\
\hline 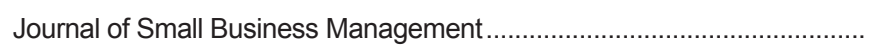 & 0 & 1 & 0 & 1 & 4 \\
\hline International Entrepreneurship and Management Journal .......................... & 0 & 0 & 2 & 2 & 9 \\
\hline Others & 3 & 4 & 5 & 12 & 53 \\
\hline \multicolumn{6}{|l|}{ Total } \\
\hline Number & 4 & 8 & 11 & 23 & 100 \\
\hline \% & 17 & 35 & 48 & 100 & - \\
\hline
\end{tabular}

other relevant journals but not from top journals in the field of entrepreneurship. All the articles selected for inclusion in the review are indicated in Table 1.

The reporting of the review is conveniently split into descriptive and thematic analysis (Tranfield et al., 2003; Vrontis \& Christofi, 2021). Gherhes et al. (2016) noted that the descriptive table should include title, area of concern, and possible contribution of the study, while thematic analysis usually proceeds by coding each article's key information adopting an indicative approach. For reliability and consistency, key info derived from the abstract and/or full text of each selected article was coded and subsequently distributed into different thematic categories. As seen in Table 2, there are four different themes developed from the thematic analysis process.

The first theme contains all those articles focused on the characteristics of entrepreneurs such as age, level of education, personal characteristics, or incentive for self-employment. In other words, mainly human development factors. This first level represents 17 percent of the total selected studies. The second theme is categorised as organisational, which focuses on industry types, firm size, and performance of entrepreneurs' ventures. 13 percent of the studies directly show a link to this level. The third level of analysis is defined as environmental, which represents 35 percent of the 23 studies selected. This level considers economic, political, and socio-cultural factors determining entrepreneurship in emerging economies. Finally, 35 percent of the reviewed studies applied more than one of these levels simultaneously; therefore, these studies constitute multilevel studies. Thus, the research builds up a 'landscape' for past and present research findings to give an overview of female entrepreneurship in emerging and/or developing economies.

\section{Review Results and Discussion}

As mentioned above, the review findings show some particular association with different levels of 
TABLE 2

\section{LEVEL OF ANALYSIS}

\begin{tabular}{|c|c|c|c|}
\hline \multirow{2}{*}{ Level of analysis } & \multicolumn{2}{|c|}{ Article } & \multirow{2}{*}{ Author and year of publication } \\
\hline & No. & $\%$ & \\
\hline Micro-individual & 4 & 17 & $\begin{array}{l}\text { Westhead \& Solesvik (2016); Zamberi Ahmad (2011); Itani et al. (2011); } \\
\text { Naser et al (2009). }\end{array}$ \\
\hline Meso-organizational & 3 & 13 & Bardasi et al. (2011); Rodríguez-Gutiérrez et al. (2014); Lee et al. (2016). \\
\hline Macro-environmental & 8 & 35 & $\begin{array}{l}\text { Tlaiss (2015); Al-Dajani \& Marlow (2010); Welsh et al. (2014, 2016); Alam et } \\
\text { al. (2011); Aidis et al. (2007); Karimi et al. (2014); Seedhouse et al. (2016). }\end{array}$ \\
\hline Multi-level & 8 & 35 & $\begin{array}{l}\text { Mehtap et al. (2017); Cavada et al. (2017); lakovleva et al. (2013); Ramadani } \\
\text { et al. (2015); Welsh et al. (2017); Tasi et al. (2016); Klyver et al. (2013); } \\
\text { Faisal et al. (2017). }\end{array}$ \\
\hline Total & 23 & 100 & \\
\hline
\end{tabular}

SOURCE: Own elaboration.

analysis clearly observable in extant research covering the field of female entrepreneurs from emerging/ developing economies. These levels are labelled in this review as micro-individual, meso-organizational, and macro-environmental, and are crucial to understand the different approaches available in the literature about this topic. Table 3 exhibits the sample studies' key findings at each level of analysis.

\section{Micro-individual level}

In several studies, human capital theory is used as a theoretical approach related to this level of analysis. Specifically, we categorised the articles according to the human developmental factors proposed by Becker (2009). The human development factors disclosed the immediate environment's vital role in a female individual's decision to involve herself in entrepreneurial activity (Becker, 2009; Faisal et al., 2017; Itani et al., 2011; Naser et al., 2009; Westhead \& Solesvik, 2016; Zamberi Ahmad, 2011).

As seen in Table 2, the review findings of microindividual represents $17 \%$ of the total number of articles of this literature review. Those articles are mostly related to two parts: first, personal characteristics (e.g., age, gender, education, etc) that explicitly and implicitly apply human capital theory as theoretical framework; second, motivation factors (e.g., employment, financial support, skills, knowledge, opportunity recognition, etc.) applying push and pull orientations through motivation theory.

With regard to the fundamental elements of human capital, many studies examined what the relationship between education and skills had to do with levels of female entrepreneurship (Mehtap et al., 2017; Naser etal., 2009; Tsai et al., 2016; Welsh et al., 2017; Westhead \& Solesvik, 2016; Zamberi Ahmad, 2011). For instance, Naser et al. (2009) noted that Western countries had found a consistent positive relationship between education and women becoming entrepreneurs. In their review from emerging (European) economies, according to Westhead and Solesvik (2016), entrepreneurial education has a significant influence on both genders in terms of propensity to start firms. Women showed less intention to start a firm than men, however educated women were more realistic and took 
TABLE 3

DESCRIPTIVE ANALYSIS OF THE INTEGRATED REVIEW STUDIES

Authors/s (year)

Aidis et al. (2007)

Alam et al. (2011)

Al-Dajani \& Marlow (2010)

Bardasi et al. (2011)

Cavada et al. (2017)

Faisal et al. (2017)

lakovleka et al. (2013)

Itani et al. (2011)

Karimi et al. (2014)

Klyver et al. (2013)

Lee et al. (2016)

Mehtap et al. (2017)
Title

Key findings
Female entrepreneurship in transition economies: the case of Lithuania and Ukraine.

An Empirical Study of Success Factors of Women Entrepreneurs in Southern Region in Malaysia.

Impact of women's home-based enterprise on family dynamics: Evidence from Jordan.

How do female entrepreneurs perform? Evidence from three developing regions.

Motivation Factors for Female Entrepreneurship in Mexico.

Strategic interventions to improve women entrepreneurship in GCC countries: a relationship modeling approach.

Financial availability and government support for women entrepreneurs in transitional economies: cases of Russia and Ukraine.

United Arab Emirates female entrepreneurs: motivations and frustrations.

Effects of role models and gender on students' entrepreneurial intentions.

Women's self-employment: An act of institutional (dis)integration? A multilevel, cross-country study.

Does gender matter in the export performance of international new ventures? Mediation effects of firm-specific and country-specific advantages.

Entrepreneurial intentions of young women in the Arab world.
Institutions play a vital role in gender variation regarding entrepreneurial entry in transition economies.

Family support, social ties, and internal motivation are significant influential factors to predict the success of female entrepreneurs.

While women prove the concept of creating a home business, they still face some cultural limitations in a patriarchal society.

Men and women differ in the size of firms they own and run, so gender gaps exist.

Various factors are associated with women becoming entrepreneurs, which are not just limited to personal threats but more to the social and economic environment as well.

This research is one of the few studies on female entrepreneurship conducted in GCC region to understand the impediments that limit the adoption of entrepreneurship as a career choice by women.

The changing environment in Russia and Ukraine have led many women to adjust to these changes in a more positive way, engorging them to entrepreneurial activity.

Society and tradition are amongst the most vital factors for women to begin entrepreneurial activities.

Role models affect entrepreneurial intention indirectly.

Gender equality has a significant relationship to a gender gap in men and women self-employment choices; therefore, this relationship is related to the country development stage and industries.

Female firm owners achieve lower export performance in comparison to males.

The weak education system and cultural barriers are the main factors that hinder women from become entrepreneurs in Jordan. 
TABLE 3 (CONTINUATION)

DESCRIPTIVE ANALYSIS OF THE INTEGRATED REVIEW STUDIES

\begin{tabular}{lll}
\hline Authors/s (year) & Title & Key findings
\end{tabular}

Naser et al. (2009)

Rodríguez-Gutiérrez et al. (2014)

Seedhouse et al. (2016)

Tlaiss (2015)

Tsai et al. (2016)

Welsh et al. (2014)

Welsh et al. (2016)

Welsh et al. (2017)

Westhead \& Solesvik (2016)

Zamberi Ahmad (2011)
Factors that affect women entrepreneurs: evidence from an emerging economy.

Female entrepreneurs in transition economies: insights from Albania, Macedonia and Kosovo.

Strategic Capabilities and Performance in Women-Owned Businesses in Mexico.

Potholes and pitfalls: The impact of rural transport on female entrepreneurs in Nigeria.

Entrepreneurial motivations of women: Evidence from the United Arab Emirates.

Refining the linkage between perceived capability and entrepreneurial intention: roles of perceived opportunity, fear of failure, and gender.

Saudi women entrepreneurs: A growing economic segment.

Influence of stages of economic development on women entrepreneurs' startups.

The influence of perceived management skill and perceived gender discrimination in launch decisions by women entrepreneurs.

Entrepreneurship education and entrepreneurial intention: Do female students benefit?

Evidence of the characteristics of women entrepreneurs in the Kingdom of Saudi Arabia: an empirical investigation.
Factors such as skills and knowledge are amongst the most critical factors to determine whether women choose to become entrepreneurs while social norms, market, network, and competition do not seem to be barriers for women in becoming entrepreneurs.

The freedom of having a choice is amongst the most essential factors to determine whether women choose to become entrepreneurs.

Entrepreneurial orientation in terms of market and learning orientation has a strong effect on female performance in Mexico.

Women believe that when the transportation system is weak in the country, it is an obstacle for them toward entrepreneurial activities.

Cultural and religious values have a stronger effect on entrepreneurial motivation, and females in the UAE and GCC have a distinguished context that reflect their characteristics.

Men have perceived capability indirectly to affect their entrepreneurial intention via perceived opportunity while women do not in Taiwan; however, there are no differences between men and women in Chinese samples.

Saudi women face several obstacles due to government and cultural restrictions; however, entrepreneurial initiatives are in increasing in Saudi Arabia amongst women.

There is a dependent relationship between female entrepreneurship and economic development across different nations.

Women in Morocco are more likely to start a business with a family member if they are perceived as having high management capabilities while gender discrimination impacts women negatively.

Entrepreneurial education students showed a higher drive for entrepreneurship than those who did not participate. While women show a lower drive to engage in entrepreneurial activities.

The educational background of Saudi women determines their skills to begin entrepreneurial activities. 
fewer risks than males. The authors suggested that entrepreneurial education is a key driver for successful performance, self-confidence, motivation, knowledge and skills. In contrast, less training and less education are claimed to be obstacles for women to become entrepreneurs. Naser et al. (2009) also contributed to this by determining the factors affecting women into becoming entrepreneurs in emerging economies by sampling women between the ages of 20 to 40 years old who resided in Middle Eastern countries. They found that younger women were optimistic about involving themselves in entrepreneurial activity and to extend their self-employment and self-accomplishment (Naser et al., 2009). While education is perceived to be a vital factor for women to increase their skills and knowledge, both educated females and less educated females were found not to be particularly attracted to entrepreneurial activity (Naser et al., 2009). Thus, the authors concluded that youth is accelerating the economic growth of emerging economies. Another study in the United Arab Emirates, however, noted that education improves skills and knowledge, which positively contributes in giving women motivation to engage in entrepreneurial activity (Tlaiss, 2015). Also, research from Saudi Arabia noted that there is a high percentage of educated Saudi women who are either attracted to working in the public sector or who are employed in the education sector (Zamberi Ahmad, 2011). Based on a study sample of females in their twenties and thirties, the author stated that Saudi female entrepreneurs believed that younger women are attracted to entrepreneurial activity. The author also found that Saudi educated females represent 58 percent of the population, yet this number has not translated into the workforce, where Saudi female participation is just 32 percent. In Jordan, however, a study found that the relationship between the education system and entrepreneurial activity needs to be more focused on the supportive learning environment than education itself as it may not be the main reason to impede women from entrepreneurial activity (Mehtap et al., 2017).
Other scholars investigate the motivation factors that impact female decision making process of becoming entrepreneurs. Specifically, the research under review demonstrates the links between skills and knowledge, and women's ability to recognise opportunities (Tsai et al., 2016; Welsh et al., 2017). Welsh et al. (2017) study amongst Moroccan women found that women in Morocco are more likely to start a business with a family member if they are perceived to have high management capabilities. Thus, this study showed that perceived skills increase the confidence of women to seek a family member for starting a business. In the same line, Tsai et al. (2016) found that amongst their sample in China and Taiwan, perceived skills increase an individual's intention to start a firm due to finding or creating opportunities. The authors implicitly conclude, however, that gender does not matter for perceived capabilities, but does in terms of opportunity recognition.

Previous analysed articles have also shown the link between how self-employment acts as a motivating factor for females in becoming entrepreneurs (Cavada et al., 2017; Klyver et al., 2013). In other words, women's choice of self-employment and understanding of the motivation of self-employment is essential to a deeper understanding of why women choose to become entrepreneurs (Cavada et al., 2017; Klyver et al., 2013). In Mexico, another research determined the factors that motivated women to self-employment (Cavada et al., 2017). The study divided the self-employment decision into two parts (push and pull) through motivation theory. A push factor represents circumstances where personal or external factors, for example losing a job due to the economic situation, make entrepreneurship a necessity. A pull factor, meanwhile, refers to the active identification of opportunities in the market. The study claimed that push factors appear to be predominant for women within developing nations while in developed countries pull factors play a greater role, with women's feelings of self-accomplishment also being a key element. 
Klyver et al. (2013) studied female self-employment across 61 countries. They claimed that to be able to understand female entrepreneurial activity at the country level, it is necessary to examine the relationship between the disintegrating choice to be entrepreneurs and integration into family. The authors also noted that self-employment can be preferable for females since it reduces dependency and increases flexibility, especially for the case of a wife or mother.

The individual-level studies, therefore, focused on human factors to understand women's motivation for becoming entrepreneurs in emerging economies. In the next section, the analysis moves towards the meso-organisational level to explore factors resulted from firm resources and capabilities and how they are related to female entrepreneurship.

\section{Meso-organisational level}

Given that, several studies sought to measure the resources and capabilities that female entrepreneurs in emerging nations need when establishing and running their firms (Bardasi et al., 2011; Lee et al., 2016; Rodríguez Gutiérrez et al., 2014). This theme focused on exploring the nature and performance of female ownership in terms of firms' size and industries (Bardasi et al., 2011; Klyver et al., 2013; Lee et al., 2016; Ramadani et al., 2015; Rodríguez Gutiérrez et al., 2014).

With regard to this level of analysis, only $13 \%$ of reviewed articles are linked to this meso-organisational level. These studies mainly used gender approach, or proposed other conceptual frameworks (e.g., the resource-based view of the firm) as key theoretical frameworks for their analysis. The findings showed that the organisational level has many relevant elements that could be used to determine female entrepreneurial activity.

Several studies acknowledge that performance depends on key resources and capabilities. For example, Bardasi et al. (2011) studied three developing nations to understand female performance in comparison to male performance, being sales the metric used to determine performance. The authors found that in all three developing regions, women operated and owned smaller firms than men. In two out of the three considered regions, female business owners were on average younger than men, but there were no differences in the age of firms to explain the variation of firm performance in years between each gender. Lastly, women in all three developing regions were attracted to a specific sector, such as retail shops or restaurants.

Lee et al. (2016) further explained the export performance of Korean women compared to men. The authors discovered that female export performance is significantly lower than that of males because firms owned by males are perceived to have higher marketing capabilities and innovation in comparison to female led ones. Venture capital is also harder to obtain for female business owners, but this in itself does not affect either women's export performance or the destination country of exports.

Another study from Mexico observed that the management capabilities of female business owners were lower in average than those of men (Rodríguez Gutiérrez et al., 2014). The authors proposed a framework to improve female management capabilities involving entrepreneurial orientation, market orientation and learning orientation. Their study concluded that such orientations are three capabilities significantly associated with increasing female performance in establishing and running a business in Mexico.

Research developed by Bardasi et al. (2011) and Rodríguez Gutiérrez et al. (2014) can be summarised into three important points. First, the resources and capabilities for women to establish and run a firm vary from country to country. Second, female entrepreneurs operate smaller ventures in comparison to men in terms of the number of employees and revenue. Third, small businesses demonstrate an essential role in terms of creating an employment opportunity as they are highly dependent on labour, supplying large firms with niche 
services or products that are complementary to their line of production, and reducing the monopoly of large firms in the market. This leads to wealth distribution that, in turn, has a positive impact on the economy at the country level.

The number of females who establish and operate businesses has been increasing over the years. This phenomenon shows that emerging and/or developing countries with high levels of unemployment and low level of gross domestic product have been diversifying their revenues to rely on more than one source, and taking the path of other developed countries by expanding the female entrepreneurial activity (lakovleva et al., 2013; Rodríguez Gutiérrez et al., 2014). According to several studies, there are a number of reasons why women create smaller firms in comparison to men some which include: ease of duplication, ease to organise and implement, ease to network or advertise through friends and family, ease to lead as a sole owner or have fewer employees to manage, easy access to finance, and increased autonomy (Bardasi et al., 2011; lakovleva et al., 2013; Lee et al., 2016; Ramadani et al., 2015; Rodríguez Gutiérrez et al., 2014).

Moving on from the resources and capabilities required for women to establish a firm, and their performance, in the following part we systematically look wider to explore different research findings concerning environmental conditions and female entrepreneurs in emerging markets contexts.

\section{Macro-environmental level}

At this level, the review of the literature showed that different environmental factors influence the probability of women becoming entrepreneurs, including government policies, culture and economy (Aidis et al., 2007; Alam et al., 2011; Al-Dajani \& Marlow, 2010; Faisal et al., 2017; lakovleva et al., 2013; Lee et al., 2016; Mehtap et al., 2017; Ramadani et al., 2015; Tlaiss, 2015; Welsh et al., 2014; Welsh, 2016).

In this macro-environmental level with $35 \%$ of reviewed studies, we found that several authors analysed the relationship between entrepreneurs and social, political, economic or institutional conditions. Concretely, this literature is related to works by Noguera et al. $(2013,2015)$ and Turro et al. (2020) that used the institutional approach to analyse the factors that affect female entrepreneurial activity in more developed contexts.

A number of macro-environmental studies try to deepen the understanding of the relationship between culture and female entrepreneurs (Alam et al., 2011; Al-Dajani \& Marlow, 2010; Karimi et al., 2014; Tlaiss, 2015). These studies explained culture as a shared system of beliefs, values, attitudes, and norms that shape individual priorities and expectations, and which distinguish them from other groups. A study from the UAE showed that the percentage of female entrepreneurs has increased over the last few years due to government support of female entrepreneurship; yet this has to be set alongside the influence of the patriarchal society in decreasing female motivation towards business entry (Tlaiss, 2015). Evidence from Jordan shared the same view of the impact of conservative patriarchal families in limiting the number of female entrepreneurs (Al-Dajani \& Marlow, 2010). More precisely, the authors' findings in respect to Palestinian women who were resident in Jordan revealed the central role of family responsibilities and how this negatively affects females' self-employment. Family and worklife balance also presents obstacles for women across Albania, Macedonia and Kosovo (Ramadani et al., 2015). Alam et al. (2011) found that the main driver of Malaysian women to entrepreneurial activity is because of the lack of opportunities in their workplace, therefore, family support, and social ties is statistically significant to motivate women towards entrepreneurial activity. Among Iranian students, meanwhile, the lack of perceived role models presents an indirect negative influence on female intention towards entrepreneurial activity. Furthermore, a study from Mexico showed that not only did conservative attitudes decrease female motivation to start a business but also a risk averse tendency, and a 
lack of family support (Cavada et al., 2017). Thus, there is widespread agreement upon the negative impact of cultural patriarchal attitudes on the propensity of women to become entrepreneurs in emerging and developing countries (Al-Dajani \& Marlow, 2010; Mehtap et al., 2017; Tlaiss, 2015).

Another theme in this body of literature examines the government and its role in helping or hindering female involvement in entrepreneurial activity (Faisal et al., 2017; lakovleva et al., 2013; Mehtap et al., 2017; Seedhouse et al., 2016). For instance, Seedhouse et al. (2016) found that Nigerian women cited a lack of government support as a key element in their lack of business growth in respect to providing a main road that is safe and accessible to different parts of the country. Mehtap et al. (2017) suggested that, to get women involved in entrepreneurial activity, the government should focus on aspects such as establishing a market structure, policies that are not inherently biased to gender, and stability. A research study across the Gulf region countries (Emirates, Qatar, Saudi Arabia, Oman, Bahrain and Kuwait) noted that the lack of a supportive regulatory environment is considered a key obstacle for women becoming entrepreneurs; in contrast, loans with a low interest rate and fewer bureaucratic procedures with lean steps attract more women toward business creation (Faisal et al., 2017). Likewise, a study from Russia and Ukraine showed that the absence of government support services such as programmes focusing on entrepreneurship to educate individuals about business environment challenges is one of the main reasons for the lack of women engaged in entrepreneurial activity (lakovleva et al., 2013).

Furthermore, various studies have shown an interest in understanding the impact of economic factors on female entrepreneurship (Aidis et al., 2007; Lee et al., 2016; Welsh et al., 2014, 2016). For example, the economic crisis that occurred in Korea in the late 1980s drove many male workers towards business creation as a substitute for their loss of income; therefore,
Korean female entrepreneurs were opportunitydriven while male entrepreneurs were more driven by necessity (Lee et al., 2016). A study showed that women in the Middle East had a less favourable attitude to entrepreneurial activity as a consequence of employment challenges that occurred in the region after the Arab Spring revolutions (Mehtap et al., 2017). Aidis et al. (2007) explored how women responded to the economic development of Lithuania and Ukraine, concluding that while memories of the Soviet Union had a significant influence in hindering female involvement in entrepreneurial activity, women gradually built the economy of their nations by increasing their entrepreneurial initiatives. Welsh et al. (2016) found that the level of economic development is statistically linked to different factors such as family support; for example, nations with factor-driven stages (whose economies are producing mostly basic products/commodities) report a definite relationship to family instrumental support on women becoming entrepreneurs.

Finally, several papers have adopted different theoretical frameworks to explain the effect of environmental factors on female individuals' decision to become entrepreneurs (Aidis et al., 2007; Alam et al., 2011; Al-Dajani \& Marlow, 2010; Faisal et al., 2017; lakovleva et al., 2013; Lee et al., 2016; Mehtap et al., 2017; Ramadani et al., 2015; Tlaiss, 2015; Welsh, 2016; Welsh et al., 2014, 2017). For instance, Welsh et al. (2017) noted that there have been various theoretical frameworks from different disciplines aiming to provide a better understanding of the female entrepreneurship phenomenon: 1) the psychological approach with the primary concentration on individual qualities (McClelland, 1961); 2) the organizational approach that seeks to analyse the impact of firm-level resources and capabilities (Ucbasaran, 2008); 3) the economic approach that determines entrepreneurs as the key players (Schumpeter, 1911); and 4) the institutional approach according to which the socio-cultural structure is paramount at establishing boundaries and guidelines needed for ruling social behavior (North, 
1990; Scott, 1995). From the perspective of our review, while several studies at the macro-environmental level show an interest in better understanding the effect of institutions to explain female entrepreneurship, actually few studies explicitly use the institutional approach (Urbano et al., 2019; Aidis et al., 2007; Lee et al., 2016).

Concisely, the following themes are evident in the studies in this area. First, government support programmes, financial support and freedom in the decision-making process are three reasons that play a vital role in motivating females towards entrepreneurial activity (lakovleva et al., 2013; Ramadani et al., 2015). Second, culture is a statistically significant indicator of female involvement in entrepreneurship (Alam et al., 2011; Al-Dajani \& Marlow, 2010; Karimi et al., 2014; Tlaiss, 2015). Furthermore, prior studies have shown that different factors constrain women to develop more business start-ups in emerging and developing nations, namely unfavourable social attitudes towards women at work, gender-arbitrary barriers in terms of support facilities, and lack of access to capital. Lastly, the Arab Spring revolution, patriarchal-oriented culture and society, and political instability usually present a negative impact on female entrepreneurship across the Middle East and North Africa (MENA) region (Kalafatoglu \& Mendoza, 2017).

\section{Conclusions}

The main objective of the study was to systematically review the existing literature on female entrepreneurial activity in emerging economies based on articles included in the Social Science Citation Index (SSCl) for the period 2008-2018. This objective arises from: 1) the scarcity of empirical evidence regarding female entrepreneurship in emerging economies, and 2) the distinctive characteristics of these emerging economies compared to highly developed ones. Our review revealed that it was possible to group the studies based on their level of analysis: micro-individual, meso-organisational or macro-environmental, although
35 percent of the reviewed papers actually combined different levels of analysis.

Thus, female entrepreneurship in the context of emerging economies have been analysed in the literature from different levels. This review study let us conclude that women's contribution to economic growth is clearly lower than men in emerging economies. The reasons for this conclusion vary from one nation to another, and depending on the different interests of each single paper. Also, many of the articles show interest in measuring the level of women-led firm growth and expansion, revenues, and number of employees. Nonetheless, it is also clear that this is an area in which there has been a gradual increase in scholarly interest but still lacks further attention.

\section{Implications}

Regarding the individual level, evidence exists in respect to the impact of human factors such as level of education, skills and, to a large extent, the necessary preparations for women to get involved in entrepreneurial activity. The findings also suggest that women with skills, knowledge and experience showed a higher probability of becoming entrepreneurs across a number of emerging economies, regardless of formal education level and age (Faisal et al., 2017; Itani et al., 2011; Naser et al., 2009; Westhead \& Solesvik, 2016; Zamberi Ahmad, 2011).

The exploratory results of this review also identified the importance of researching the characteristics and performance of women ownership in respect to firm size and industry operated in. The different reviewed documents confirm that women entrepreneurs, in general, were especially attracted to the service sector and tend to own smaller firms in comparison to men. Again, the reasons vary according to each paper, but it can be summarised into these categories: experience and skills that females tend to excel on, ease of replication, arrangement and implementation, ease to network or advertise through friends and 
family, ease to lead as a sole owner or have fewer employees to manage, easy access to finance, and increased autonomy. The results also indicate that there is some level of government support to small businesses with facilitation policies that distinguish them from large corporations; for example, a certain willingness to provide a lower rate of interest for credit and loans. Besides, new digital technologies have the potential to democratize entrepreneurship and even promote international expansion by providing access to international market knowledge and establishing interactions with customers and partners. In a recent study conducted among a sample of 300 Bulgarian SMEs from a gender perspective, Pergelova et al. (2019) examine how digital technologies affect their international expansion showing that female entrepreneurs leverage the enabling effects of digital technologies even more than their male counterparts.

Meanwhile, at the macro-environment level several studies have identified a number of different factors that may help or hinder female entrepreneurship in emerging economies. These various macro-level factors act under the umbrella of government policies, culture, and economy, which affect the probability of women becoming entrepreneurs. Besides, from this review, the environmental factors usually show the highest impact on the decision of women to become entrepreneurs in this context, with social and cultural aspects affecting women entrepreneurship in emerging and developing countries even more than political and economic ones. For example, the reviewed literature demonstrated that one of the main factors associated with female entrepreneurs is their attitude within patriarchal societies. The patriarchal society levels differs vastly between emerging economies. In addition, Arab societies are considered highly patriarchal societies in comparison to other nations within emerging economies. This result could be related to the Arab heritage and Islamic civilization (Badawi, 1995). Taking all these factors into consideration will increase the understanding of the reasons behind the driving macro-level factors for female entrepreneurs.

\section{Limitations and Future Research}

Several limitations of this study have to be acknowledged. The articles were retrieved from the Web of Science database only; therefore, the results are limited to this database, which may exclude many other publications from other journals. In addition, the study is limited to the scope of the keywords used to identify the journal papers, which might have also limited their number. Besides, as explained by Gherhes et al. (2016), Thorpe et al. (2005), and Tranfield et al. (2003), the systematic review approach is better applicable for topics with a vast body of accumulated knowledge than perhaps the one visible in our review field. Nevertheless, our systematic review also allow us to identify several future research directions that are briefly outlined below.

First, the results of this study call for more contextualised and operational variables to fit the specific nation at focus. Most of the reviewed papers showed a lack of operationalisation of variables; for example, key factors within developed countries may differ to those in emerging economies due to the difference in culture and different parameters used to measure success. Scholars suggest that future studies should seek to contextualise the study of female entrepreneurs within the specific cultural environment of targeted nations. In fact, the results of this paper suggest that environmental factors have the highest impact on female entrepreneurs; therefore, investigating the influence of social, political, cultural, and economic differences between different nations may help understand how female entrepreneurs can be better assisted.

Second, results from the analysis show that most of the papers lacked an explicit theoretical framework in order to explain female entrepreneurial activity. For example, some studies at the macro-environmental influences on female entrepreneurs tend to make an implicit use of the institutional theory, but do not implement this approach explicitly. This suggests a need 
for a more explicit institutional theory-based analysis of the phenomenon of female entrepreneurship in emerging and/or developing economies. This, in turn, reflects on the need for a deeper understanding of the institutional environment in these countries.

Third, with respect to the debate on whether female entrepreneurs tend to be attracted to smaller sized firms and mainly the service sector, the review results confirm that women tend to own smaller firms in comparison to men. The review of literature also reveals that the performance of men-led firms is generally higher than the ones owned by women in emerging countries. This suggests interesting avenues for future studies in terms of trying to understand how innovation and market changes may affect female entrepreneurial performance within emerging nations.

Fourth, since relatively few studies have been undertaken into female entrepreneurs from the organisational (meso) level, the review results also suggest that future studies need to focus more on this particular area so as to better explain the key resources and capabilities needed by female entrepreneurs in emerging economies which may also impact the way they choose to start operating, the size of their firms, and their expanding decisions. More precisely, the development of women's capabilities to start and run their firms should count with higher institutional support in the form of training programmes and information to sustain those segments of the market with the potential to grow, and this offers a line for future studies interested in economic development from a gender perspective.

Finally, with respect to most of the empirical papers selected, the perceived weaknesses of some of their empirical findings can be also related to an inadequate use of statistical analysis techniques. So, future studies should develop more solid empirical work in order to validate and give more reliability to their findings. Future scholars should get a stronger base of empirical evidence related to the entrepreneurial environment relevant for women in emerging economies by seeking larger samples and using more advanced methodologies to explain the complex relationships being involved. Besides, policymakers within developing and emerging economies should also take the initiative to devote more attention and invest in promoting female entrepreneurial activity as there is a particularly marked gender gap in most of these countries.

\section{Bibliographic references}

Aidis, R., Welter, F., Smallbone, D., \& Isakova, N. (2007). Female entrepreneurship in transition economies: The case of Lithuania and Ukraine. Feminist Economics, 13(2), 157-183.

Alam, S. S., Jani, M. F. M., \& Omar, N. A. (2011). An empirical study of success factors of women entrepreneurs in southern region in Malaysia. International Journal of Economics and Finance, 3(2), 166-175.

Al-Dajani, H., \& Marlow, S. (2010). Impact of women's home-based enterprise on family dynamics: Evidence from Jordan. International Small Business Journal, 28(5), 470-486.

Álvarez, C., Urbano, D., \& Amorós, J. E. (2014). GEM research: Achievements and challenges. Small Business Economics, 42(3), 445-465.

Aparicio, S., Urbano, D., \& Audretsch, D. (2016). Institutional factors, opportunity entrepreneurship and economic growth: Panel data evidence. Technological Forecasting and Social Change, 102, 45-61.

Badawi, J. A. (1995). Gender equity in Islam (Vol. 2). IDM Publications.

Bardasi, E., Sabarwal, S., \& Terrell, K. (2011). How do female entrepreneurs perform? Evidence from three developing regions. Small Business Economics, 37(4), 417-441.

Bashir, M., Naqshbandi, M. M., \& Farooq, R. (2020). Business model innovation: A systematic review and future research directions. International Journal of Innovation Science, 12(4), 457-476.

Becker, G. S. (2009). Human capital: A theoretical and empirical analysis, with special reference to education. University of Chicago press.

Bosma, N. S., \& Levie, J. (2010). Global Entrepreneurship Monitor 2009 Executive Report.

Cavada, M. C., Bobek, V., \& Maček, A. (2017). Motivation factors for female entrepreneurship in Mexico. Entrepreneurial Business and Economics Review, 5(3), 133-148.

Devece, C., Peris-Ortiz, M., \& Rueda-Armengot, C. (2016). Entrepreneurship during economic crisis: Success factors and paths to failure. Journal of Business Research, 69(11), 5366-5370.

Faisal, M. N., Jabeen, F., \& Katsioloudes, M. I. (2017). Strategic interventions to improve women entrepreneurship in GCC 
countries: A relationship modeling approach. Journal of Entrepreneurship in Emerging Economies, 9(2), 161-180.

GEM, Global Entrepreneurship Monitor. (2017). Women's Entrepreneurship 2016/2017 Report.

Gherhes, C., Williams, N., Vorley, T., \& Vasconcelos, A. C. (2016). Distinguishing micro-businesses from SMEs: A systematic review of growth constraints. Journal of Small Business and Enterprise Development, 23(4), 939-963. https://doi. org/10.1108/JSBED-05-2016-0075

lakovleva, T., Solesvik, M., \& Trifilova, A. (2013). Financial availability and government support for women entrepreneurs in transitional economies: Cases of Russia and Ukraine. Journal of Small Business and Enterprise Development, 20(2), 314-340.

Itani, H., Sidani, Y. M., \& Baalbaki, I. (2011). United Arab Emirates female entrepreneurs: Motivations and frustrations. Equality, Diversity and Inclusion: An International Journal, 30(5), 409-424.

Kalafatoglu, T., \& Mendoza, X. (2017). The impact of gender and culture on networking and venture creation: An exploratory study in Turkey and MENA region. Cross Cultural \& Strategic Management, 24(2), 332-349.

Karimi, S., Biemans, H. J. A., Lans, T., Chizari, M., \& Mulder, M. (2014). Effects of role models and gender on students' entrepreneurial intentions. European Journal of Training and Development, 38(8), 694-727.

Klyver, K., Nielsen, S. L., \& Evald, M. R. (2013). Women's self-employment: An act of institutional (dis)integration? A multilevel, cross-country study. Journal of Business Venturing, 28(4), 474-488.

Lee, I. H., Paik, Y., \& Uygur, U. (2016). Does gender matter in the export performance of international new ventures? Mediation effects of firm-specific and country-specific advantages. Journal of International Management, 22(4), 365-379.

McClelland, D. C. (1961). Characteristics of the Entrepreneurs. In D. C. McClelland (ed.), The Achieving Society (pp. 259-300). D. Van Nostrand Company, Inc.

McGrath, A. (2006). RefWorks investigated: An appropriate bibliographic management solution for health students at King's College London? Library and Information Research, 30(94), 66-73.

Mehtap, S., Pellegrini, M. M., Caputo, A., \& Welsh, D. H. B. (2017). Entrepreneurial intentions of young women in the Arab world: Socio-cultural and educational barriers. International Journal of Entrepreneurial Behavior \& Research, 23(6), 880-902.

Moreira, J., Marques, C. S., Braga, A., \& Ratten, V. (2019). A systematic review of women's entrepreneurship and internationalization literature. Thunderbird International Business Review, 61(4), 635-648.

Moustaghfir, K., Ramid, S., \& Touhs, K. (2020). Linking human resource management, entrepreneurial orientation, and firm performance: An integrative theoretical framework. International Journal of Innovation and Learning, 28(3), 394414. https://doi.org/10.1504/IJIL.2020.109843

Naser, K., Mohammed, W. R., \& Nuseibeh, R. (2009). Factors that affect women entrepreneurs: Evidence from an emerging economy. International Journal of Organizational Analysis, 17(3), 225-247.

Noguera, M., Álvarez, C., \& Urbano, D. (2013). Socio-cultural factors and female entrepreneurship. International Entrepreneurship and Management Journal, 9(2), 183-197.

Noguera, M., Álvarez, C., Merigó, J. M., \& Urbano, D. (2015). Determinants of female entrepreneurship in Spain: An institutional approach. Computational and Mathematical Organization Theory, 21(4), 341-355.

North, D. C. (1990). Institutions, economic theory and economic performance. Institutions, Institutional Change and Economic Performance. Cambridge University Press.

Pergelova, A., Manolova, T., Simeonova-Ganeva, R., \& Yordanova, D. (2019). Democratizing entrepreneurship? Digital technologies and the internationalization of female-led SMEs. Journal of Small Business Management, 57(1), 14-39.

Ramadani, V., Hisrich, R. D., \& Gërguri-Rashiti, S. (2015). Female entrepreneurs in transition economies: Insights from Albania, Macedonia and Kosovo. World Review of Entrepreneurship, Management and Sustainable Development, 11(4), 391-413.

Rodríguez Gutiérrez, P., Fuentes Fuentes, M. del M., \& Rodríguez Ariza, L. (2014). Strategic Capabilities and Performance in Women-Owned Businesses in Mexico. Journal of Small Business Management, 52(3), 541-554.

Schumpeter, J. A. (1911). The theory of economic development. Harvard Economic Studies, 46. Harvard University Press.

Scott, W. R. (1995). Institutions and Organizations. Ideas, Interests and Identities. Sage.

Seedhouse, A., Johnson, R., \& Newbery, R. (2016). Potholes and pitfalls: The impact of rural transport on female entrepreneurs in Nigeria. Journal of Transport Geography, 54, 140-147.

Stephen, F. H., Urbano, D., \& van Hemmen, S. (2005). The impact of institutions on entrepreneurial activity. Managerial and Decision Economics, 26(7), 413-419.

Thorpe, R., Holt, R., Macpherson, A., \& Pittaway, L. (2005). Using knowledge within small and medium-sized firms: A systematic review of the evidence. International Journal of Management Reviews, 7(4), 257-281.

Tlaiss, H. A. (2015). Entrepreneurial motivations of women: Evidence from the United Arab Emirates. International Small Business Journal, 33(5), 562-581.

Tranfield, D., Denyer, D., \& Smart, P. (2003). Towards a methodology for developing evidence-informed management knowledge by means of systematic review. British Journal of Management, 14(3), 207-222. 
Tsai, K. H., Chang, H. C., \& Peng, C. Y. (2016). Refining the linkage between perceived capability and entrepreneurial intention: Roles of perceived opportunity, fear of failure, and gender. International Entrepreneurship and Management Journal, 12(4), 1127-1145.

Turro, A., Noguera, M., \& Urbano, D. (2020). Antecedents of entrepreneurial employee activity: does gender play a role? International Journal of Entrepreneurial Behavior \& Research, 26(8), 1685-1706.

Ucbasaran, D. (2008). The fine 'Science' of entrepreneurial decision-making. Journal of Management Studies, 45(1), 221-237.

Urbano, D., \& Álvarez, C. (2014). Institutional dimensions and entrepreneurial activity: an international study. Small Business Economics, 42(4), 703-716.

Urbano, D., Aparicio, S., \& Audretsch, D. (2019). Twenty-five years of research on institutions, entrepreneurship, and economic growth: What has been learned? Small Business Economics, 53(1), 21-49.

Vrontis, D., \& Christofi, M. (2021). R\&D internationalization and innovation: A systematic review, integrative framework and future research directions. Journal of Business Research, 128, 812-823.
Welsh, D. H. B. (2016). Women-owned family businesses in Africa: Entrepreneurs changing the face of progress. In $\mathrm{M}$. Acquaah (ed.), Family Businesses in Sub-Saharan Africa (pp. 155-173). Springer.

Welsh, D. H. B., Kaciak, E., \& Minialai, C. (2017). The influence of perceived management skills and perceived gender discrimination in launch decisions by women entrepreneurs. International Entrepreneurship and Management Journal, 13(1), 1-33.

Welsh, D. H. B., Kaciak, E., \& Thongpapanl, N. (2016). Influence of stages of economic development on women entrepreneurs' startups. Journal of Business Research, 69(11), 4933-4940.

Welsh, D. H. B., Memili, E., Kaciak, E., \& Al Sadoon, A. (2014). Saudi women entrepreneurs: A growing economic segment. Journal of Business Research, 67(5), 758-762.

Westhead, P., \& Solesvik, M. Z. (2016). Entrepreneurship education and entrepreneurial intention: Do female students benefit? International Small Business Journal, 34(8), 9791003.

Zamberi Ahmad, S. (2011). Evidence of the characteristics of women entrepreneurs in the Kingdom of Saudi Arabia: An empirical investigation. International Journal of Gender and Entrepreneurship, 3(2), 123-143. 